\title{
Irregular past tense forms in English: how data from children with specific language impairment contribute to models of morphology
}

\author{
Chloë R. Marshall · Heather K. J. van der Lely
}

Received: 12 December 2010/Accepted: 12 December 2010/Published online: 4 January 2012

(C) The Author(s) 2011. This article is published with open access at Springerlink.com

\begin{abstract}
Two cognitive models of inflectional morphology are widely debated in the literature - the Words and Rules model, whereby irregular forms are stored in the lexicon but regular forms are created by rule, and Single Mechanism models, whereby both regulars and irregulars form an associative network, with no rules. A newer model, the Computational Grammatical Complexity (CGC) model, recognises the contribution of hierarchical complexity in three components of the grammar, syntax, morphology and phonology, to the construction of morphologically complex forms. This model has previously been tested for regular past tense inflection in English, and in this study we test its predictions for the English irregular past tense, in four groups of children: a group with Grammatical Specific Language Impairment (G-SLI; aged 9;8-17;8), and three groups of typically developing children (aged 5;4-8;5). Children with G-SLI provide an important test case for the CGC model because they have deficits in syntax, morphology and phonology. As predicted, children with G-SLI produced fewer tense-marked irregulars than expected for their age, and fewer over-regularisations than their
\end{abstract}

C. R. Marshall · H. K. J. van der Lely

Centre for Developmental Language Disorders and Cognitive Neuroscience,

London, UK

C. R. Marshall

Department of Psychology and Human Development, Institute of Education,

University of London, London, UK

H. K. J. van der Lely ( $\square)$

Department of Psychology, Harvard University, William James Hall, 33 Kirkland Street,

Cambridge, MA 02138, USA

e-mail: h.vanderlely@dldcn.org

H. K. J. van der Lely

Psychological Sciences Research Institute, Université Catholique de Louvain,

Louvain-la-Neuve, Belgium 
language-matched controls. The effect of verb-end phonology on over-regularisation and null-marking errors was the same for all groups: both G-SLI and typically developing children were more likely to over-regularise verbs ending in a vowel, and more likely to null-mark verbs ending in an alveolar consonant. We interpret these results as providing further support for the CGC model.

Keywords Grammatical-Specific Language Impairment · Inflectional morphology · Over-regularisation · Phonology

\section{Introduction}

\subsection{Models of inflectional morphology}

The cognitive processes underlying inflectional morphology have been, and continue to be, hotly debated (for a review, see Pinker 1999). Much research has focused on the English past tense, for which verbs fall into two groups: those that take a regular suffix -ed (e.g. walked, jogged) and those that take an irregular form (e.g. ran, flew). One view of cognition, the dual mechanism or "words and rules" (WR) model, claims that these two groups of verbs are processed in different ways: regulars by a morphological rule that adds the suffix to a verb stem, and irregulars by retrieval of an idiosyncratic form from the lexicon (Marcus et al. 1992; Pinker and Ullman 2002; Ullman 1999, inter alia). The alternative, single mechanism (SM), view claims that regulars and irregulars are processed using the same cognitive system: a patternassociated memory where there are no rules, only a network of links between simple processing units (Kielar et al. 2008; McClelland and Patterson 2002; Rumelhart and McClelland 1986, inter alia).

Data from individuals with morphological impairments have been brought to bear on the debate between the WR and SM models (Braber et al. 2005; MarslenWilson and Tyler 1997, inter alia). Adults with anomia, who are impaired in wordfinding and typically have damage to the posterior perisylvian region of the left hemisphere (i.e. Wernicke's area), find irregular past tense forms harder to produce than regulars. In contrast, patients with agrammatism, who have typically undergone damage to the anterior perisylvian region (which includes Broca's area), have more difficulty with regulars and also have difficulty inflecting nonsense words (e.g. wugged). This double dissociation has been presented as evidence that "words" and "rules" are not only cognitively distinct, but are subserved by different neural systems (Ullman et al. 1997).

An alternative interpretation of these data has been offered by Joanisse and Seidenberg (1999), who modelled the double dissociation in a connectionist network. They were able to produce a model that had particular difficulty with inflected nonsense forms by damaging the speech output layer to simulate a phonological deficit, whereas simulating a semantic deficit by damaging the semantic layer of the model produced the opposite pattern - a marked difficulty in producing irregular past tense forms. Joanisse and Seidenberg therefore suggested that the patients in 
Ullman et al.'s study were suffering differential damage to the semantic and phonological codes that are characteristic of all words, and that no "rules" were needed to explain their differential performance. More recently, Ullman and colleagues have countered with a more rigorously controlled study of aphasic patients, showing that the double dissociation between regulars and irregulars remains even when frequency, phonological complexity and articulatory difficulty are held constant between the two types of verb, consistent with the predictions of the WR model (Ullman et al. 2005).

Data from children with Specific Language Impairment (SLI) have also been used by both sides of the WR/SM debate. SLI is a severe deficit in acquiring language, despite normal non-verbal cognition, unimpaired sensory processing and an adequate language-learning environment, that is present in approximately $7 \%$ of children (Leonard 1998). There has been particular interest in the morphological impairments that appear to characterise this population, notably impairments in tense marking. SLI has been most extensively studied in English, and in this language, children with SLI perform particularly poorly on tense morphology (Leonard et al. 1992; Oetting and Horohov 1997; Rice 2003; van der Lely and Ullman 2001). They use tense marking inconsistently, omitting it, to varying extents, from contexts where it is obligatory. They also perform poorly on grammaticality judgment tasks, being more likely than typically developing children to accept unmarked forms of both regular and irregular verbs (van der Lely and Ullman 1996). As a result, a deficit in tense-marking has been argued to be a clinical marker for SLI in English (Rice and Wexler 1996).

The past tense impairment in SLI affects regular forms more severely than irregulars. Whereas typically developing children show a regularity advantage in that they are more likely to tense mark regulars than irregulars, children with Grammatical(G)-SLI (a type of SLI characterised by particularly severe grammatical deficits) demonstrate no such advantage (van der Lely and Ullman 2001). Moreover, children with G-SLI show a significant correlation between past tense frequency and inflectional accuracy for regular verbs, suggesting that these forms are stored, whereas there was no such correlation for typically developing children. Van der Lely and Ullman interpreted these two findings as indicating that children with G-SLI have an impairment specific to rule use, and therefore rely on the storage of past tense forms, essentially treating regulars as irregulars and learning them item by item. They argued that this is consistent with a WR model of morphology.

Van der Lely and Ullman's interpretation of their results has not been universally accepted. For example, Joanisse (2004) claims to be able to model a similar pattern of performance using connectionist models that simulate a phonological deficit. Given evidence that many children with SLI have a phonological deficit that affects speech perception and phonological working memory, it is not unreasonable to propose that an underlying deficit in auditory processing and phonology impairs regular past tense forms more severely than irregulars due to the low perceptual salience of the suffix (see also Joanisse and Seidenberg 1998).

In an attempt to tease apart the two models, Marshall and van der Lely (2006) compared how well children with G-SLI were able to inflect two different types of 
regular past tense forms. One set of verbs contained clusters at the inflected verb end that can also occur in monomorphemic English words ("monomorphemically legal clusters", e.g. missed (c.f. mist) wrapped (c.f. rapt)). The other set contained clusters that can only occur in inflected verbs ("monomorphemically illegal clusters", e.g. those at the end of hugged, buzzed and fished). In structural terms the phonological complexity of these two types of clusters is the same, but they differ in whether or not the cluster signals a morpheme boundary. Marshall and van der Lely hypothesised that if children with G-SLI do indeed rely on storage for their production of regular past tense forms, then the frequency of the cluster will be important-forms with legal clusters will be produced with greater accuracy than forms with illegal clusters because legal clusters are more frequent (as they occur in both inflected and uninflected words). Importantly, if typically developing children have access to a morphological rule, then frequency effects will leave no signature on past tense inflection-children will be just as accurate at producing past tense forms with illegal and with legal clusters. This is indeed what Marshall and van der Lely found, and they interpreted this as further evidence for children with SLI having an impairment specific to a morphological rule.

A further finding from Marshall and van der Lely's 2006 study was that one of the groups of typically developing children actually had a significantly higher inflection rate for verbs with illegal clusters in their inflected form. This led Marshall and van der Lely to speculate on an explanation involving morphological parsing: illegal clusters betray a verb's inflectional status, and might therefore serve as a learning cue for typically developing children. If children with G-SLI have a morphological deficit, they would not be able to make use of this phonotactic cue, and this would affect not only the production of regular inflected forms, but also their comprehension.

Marshall and colleagues tested this prediction by investigating the comprehension of passive sentences in children with G-SLI and typically developing children (Marshall et al. 2007). In order to interpret a reversible passive sentence such as the squirrel was bathed by the tortoise, and to assign thematic roles correctly, the child needs to parse the participle into stem + suffix and interpret the aspectual feature of the suffix in relation to the tense marker (the auxiliary). Marshall and colleagues hypothesised that for typically developing children, who are able to represent a morphologically complex form as stem + suffix, illegal clusters would provide a cue to the existence of a stem + suffix boundary, and that interpretation would be more accurate than when the participle had a legal cluster. This was indeed the case: typically developing children were more accurate at identifying who did what to whom in passives where the past participle had an illegal cluster. In contrast, the children with G-SLI showed no differences in comprehension accuracy as a function of the cluster's phonotactics. Again, Marshall and colleagues interpreted this result as further evidence that children with G-SLI have a morphological deficit, consistent with the WR model.

At the same time, morphology is not the only factor affecting how successful children with G-SLI are at inflecting regular verbs: phonology also needs to be taken into account, something that is lacking in current WR accounts. Marshall and van der Lely (2007a) showed that children with G-SLI are less successful at inflecting 
regular verbs when a cluster would be created (e.g. hugged, jumped) than when no cluster results (e.g. weighed, chewed). This pattern was predicted from the finding that children with G-SLI, despite no overt articulation difficulties, have difficulty repeating syllabically complex non-words (Gallon et al. 2007).

This pattern of phonology impacting on inflected forms is also found in typical development. Even in typical development the acquisition of inflectional morphology is protracted, and among the factors that contribute to this protraction is phonology. For example, in a recent study of 3rd person singular inflection, Song et al. (2009) noted that in both spontaneous conversation and an experimental task, 2 year-olds are less likely to inflect verb stems ending in a consonant than those ending in a vowel. Polite (2011) obtained similar findings in spontaneous language samples from typically developing children aged 2-4 years. Similarly, it has been known for a long time that children avoid using the syllabic past tense, third person singular, possessive and plural suffixes (i.e. the suffixes in needed, (she) watches, Jess's (hat), and witches). In the classic "wug" study of morphological productivity, in which typically-developing 4-7 year-olds were asked to inflect nonsense words with a variety of morphemes, Berko (1958) noted that children are less likely to pluralise nonsense nouns that required the syllabic suffix (e.g. tass), a pattern that extends to nonsense nouns requiring the syllabic possessive suffix, and to nonsense verbs requiring the syllabic past tense or syllabic 3rd person singular suffix. This finding was replicated by Matthews and Theakston (2006) for real plural nouns. Bybee and Slobin (1982) similarly found that although preschoolers are able to productively inflect verbs for the past tense, they are less likely to inflect stems ending in $/ \mathrm{t} /$ or $/ \mathrm{d} /$. A popular interpretation is the "affix-checking" hypothesis; children avoid adding a suffix to a stem that already appears to be inflected because it ends in a $/ t /$ or $/ d /$ (in the case of a past tense suffix) or a $/ \mathrm{s} /$ or $/ \mathrm{z} /$ (in the case of the plural, third person singular or possessive) (Berko 1958; Bybee and Slobin 1982).

With respect to irregular past tense formation, phonology also has a role to play. Bybee and Slobin (1982) found that although young children frequently overregularise irregular past tense forms when they do not know the correct form (e.g. goed, telled), they are less likely to over-regularise /t/- or /d/-final stems (e.g. ride, sit). Marchman (1997) also reported these effects.

Phonological effects on irregular past tense forms in children with G-SLI have hitherto not been investigated, even though doing so would further test the WR and SM models of morphology. The reason is that although irregular past tense formation does not involve suffixation per se, when a child fails to retrieve the correct irregular form, there are two principal strategies available to him/her: production of a null-marked form (i.e. the verb stem), or over-regularisation. Children with a morphological deficit, such as those with G-SLI, are predicted not to over-regularise to the same extent as typically developing children. Yet for both groups an effect of phonology, similar to what has been reported for regular inflected forms, would be predicted to be found on any over-regularisations and null-marked forms that do occur.

In the present study we investigate the effects of morphology and phonology on irregular past tense forms, comparing a group of children with G-SLI to groups of 
younger, typically developing children matched for overall language abilities. In the remainder of this introduction we do two things: we set out what is known about the acquisition of irregular morphology, and we motivate our study within the framework that we have proposed for the deficit in G-SLI: the Computational Grammatical Complexity model. This model is consistent with the WR account of morphology, but additionally acknowledges that phonology is an important factor in how accurately children are able to produce inflected forms.

\subsection{The acquisition of the English irregular past tense}

The acquisition of the English irregular past tense has long fascinated researchers of language development. Brown, in his classic study of morphological development, found that the irregular past tense was mastered relatively early in the sequence of English morphemes, and before the regular past tense (Brown 1973). De Villiers and de Villiers (1973) replicated these findings in a larger sample of children. Other researchers have since shown, however, that the irregular past tense has a very protracted acquisition path, developing well into the early school years (Marchman 1997; Marcus et al. 1992; Matthews and Theakston 2006; Shipley et al. 1991).

There are approximately 180 irregular past tense forms in English, and while some of these are archaic and used only very infrequently (e.g. smite-smote, bid-bade), others (e.g. go-went, take-took, come-came) are amongst our most frequently used verbs (Pinker 1999). Irregulars, being generally unpredictable in form, ${ }^{1}$ have to be memorised individually. In contrast, regulars are predictable, and so do not need to be memorised - they can be created anew each time. As we have seen, the extent to which speakers of a language have an abstract "rule" for regular inflection, and how such a rule might develop in children, is a topic of current debate in SLI research and in cognitive science more generally (e.g. Joanisse 2004; Marshall and van der Lely 2006). However, whatever their stance on regular verbs, the vast majority of researchers agree that irregular past tense forms have to be learnt through memorisation. When children fail to retrieve an irregular form, they tend to provide one of two erroneous forms: either an over-regularisation (i.e. verb $+-e d$ ) or a null-marked form.

Given that some irregular forms will be encountered only infrequently, it is not surprising that learning the full set takes children many years (Shipley et al. 1991). What is perhaps more surprising is that when children start to over-regularise, they do not do so consistently, and null-marked forms and over-regularisations persist side-by-side for many years (Matthews and Theakston 2006). The persistence of both null-marked and over-regularised forms has been shown to be due, in part, to the verb's phonology (Matthews and Theakston 2006; Shipley et al. 1991; Marchman et al. 1999). Furthermore, for children with SLI, the effects of phonology last for longer than is the case for typically developing children. Marchman, Wulfeck and Weismer's (1999) past tense study revealed that children with SLI aged 6-12 make more bare stem errors for regular verbs ending in /t/ and /d/ than for

\footnotetext{
1 There are certain family resemblance categories, for example keep-kept, creep-crept, sleep-slept, sweep-swept and weep-wept, but even these have regular competitors, e.g. peep-peeped, seep-seeped, beep-beeped, cheep-cheeped.
} 
stems ending in a non-alveolar stop consonant, and that these same phonological pressures are at play for irregulars - they make fewer over-regularisations and more null-marking errors when stems end in a / $/$ / or /d/ than when stems end in a nonalveolar stop consonant. For typically developing children of the same age, however, there is no such effect of phonology, for either regulars or irregulars.

No studies of irregular past tense formation have yet investigated both phonological effects that are known to affect regulars in children with SLI: syllabic complexity at the inflected verb end, and the syllabic infection /Id/. The present study fills this gap.

\subsection{The Computational Grammatical Complexity model}

We base this study within a particular theoretical framework, the Computational Grammatical Complexity (CGC) model that recognises the contributions of syntactic, morphological and phonological complexity to past tense inflection. The model has come out of a series of studies of a particular subgroup of children with SLI, those with G-SLI. Children with G-SLI have severe and persisting impairments not only in inflectional morphology, but also with structures that require syntactic dependencies, such as pronominal reference, the passive, wh-questions and relative clauses (for a review, see van der Lely and Marshall 2011). They also have difficulty with certain phonological structures, such as consonant clusters and unfooted syllables (Gallon et al. 2007). The CGC model (van der Lely 2005; van der Lely and Marshall 2011) proposes that deficits in building hierarchical structures within three components of the grammar, namely morphology, syntax and phonology, all impact on language in G-SLI, and that linguistic constructions are impaired as a function of their complexity in those three components.

Furthermore, although the CGC model was developed on the basis of studies of a particular group of children with SLI, it is claimed to be a model of language for both typically developing children and children with other forms of SLI. The central tenet is that certain language structures, such as the English regular past tense, require complexity in syntax, morphology and phonology. Inflections will not be produced or understood consistently until complexity in those three components has been mastered, and an impairment in one or more of those components of the grammar will impact on children's inflectional accuracy (Marshall and van der Lely 2007a, van der Lely 2005; van der Lely and Marshall 2011).

What concerns us in the context of this paper is the CGC model's prediction that phonology will impact on SLI children's realisation of suffixed forms independently of deficits in two other grammatical components of language: syntax and morphology. Yet importantly, and in contrast to SM models of morphology, phonological deficits are not the sole cause of inflectional impairments in children with SLI.

With respect to irregular past tense formation in children with G-SLI and in typically developing children, the CGC model makes the following predictions:

- Syntactic deficit: With respect to tense, the syntactic deficit is proposed to lie in the hierarchical dependency, between phrases but within the clause level, that is required for feature movement/checking from V to I. Children with G-SLI are 
therefore predicted to produce fewer forms marked for tense than typically developing children. Tense can be marked in one of two ways-either by producing the correct form (e.g. throw-threw) or by producing an over-regularisation error (e.g. throw-throwed). Children with G-SLI are predicted to produce fewer tense-marked irregulars (i.e. correct forms + over-regularisations) and more nontensed (e.g. throw-throw) forms than typically developing children.

- Morphological deficit: Suffixed forms (e.g. throwed) are hierarchically complex, and therefore children with G-SLI are predicted to produce fewer over-regularisation errors than typically developing children.

- Phonological deficit: The avoidance of clusters and the syllabic suffix, which require hierarchical structures at the syllable and foot levels respectively, will impact on both the number of over-regularisations (more over-generalisations for phonologically simple forms, e.g. throwed, than complex forms, e.g. shaked, fighted) and the number of null-marking errors (more null-marking errors for complex forms).

\section{Methodology}

\subsection{Participants}

13 children with G-SLI (aged 9;8-17;8) participated in the study. They were selected on the basis of a persistent deficit in grammatical production and comprehension, as revealed by standardised language tests and by tests designed specifically to target the complex grammatical structures that this group find so difficult. The precise selection criteria for G-SLI are well-documented and so will not be repeated here (see van der Lely et al. 1998; van der Lely and Stollwerck 1997). 8 of the children had also participated in the studies reported in Marshall and van der Lely (2006, $2007 \mathrm{a}, \mathrm{b})$, but the studies reported here took place 12 months later.

The performance of the G-SLI group is compared to that of typically developing children. The reasons for this are two-fold: first, to obtain a picture of normal development, and second, to compare whether children with G-SLI show quantitative and qualitative differences in inflectional morphology compared to typically developing children. The most suitable choice of control matches is not straightforward. There is little to be gained from selecting chronological age matches for language tasks because children with SLI by definition perform more poorly (although age-matches are appropriate for non-linguistic tasks). Chronological age matches for the G-SLI participants in the present study would need to be aged between 9 and 17, and yet typically developing 8 -year-olds complete irregular past tense elicitation tasks with high levels of accuracy (e.g. Shipley et al. 1991, 86\% correct). Using language-matches, however, is informative because it allows us to determine whether poor performance on experimental tasks is to be expected given the G-SLI group's general low language level, or whether the experimental task has identified an area of deficit above and beyond that expected for their general language level (the "delay within a delay" model, Rice, 2003).

Our control participants were all chosen to have English as a first language, no history of a speech and language disorder, and no history of hearing impairment, as reported by 
teachers and parents. Two tests of language comprehension were used for matching: the Test of Receptive Grammar (TROG; Bishop 1983) and the British Picture Vocabulary Scales (BPVS; Dunn et al. 1997). Both are picture pointing tasks, whereby the child hears a sentence (in the case of the TROG) or a word (in the case of BPVS) and has to choose which of four pictures best matches that sentence/word. The ages of the different participant groups, and their language scores, are reported in Table 1.

Table 1 Participants

\begin{tabular}{lllll}
\hline Measure & $\begin{array}{l}\text { G-SLI } \\
(N=13)\end{array}$ & $\begin{array}{l}\text { LA1 controls } \\
(N=12)\end{array}$ & $\begin{array}{l}\text { LA2 controls } \\
(N=12)\end{array}$ & $\begin{array}{l}\text { LA3 controls } \\
(N=12)\end{array}$ \\
\hline Age & & & & \\
Mean & $13 ; 5$ & $6 ; 0$ & $7 ; 1$ & $8 ; 2$ \\
Range & $9 ; 8-17 ; 8$ & $5 ; 4-6 ; 6$ & $6 ; 7-7 ; 6$ & $7 ; 9-8 ; 5$ \\
TROG & & & & 17.17 \\
Raw, mean & 12.62 & 14.53 & $14-19$ & $15-19$ \\
Raw, range & $6-17$ & $12-17$ & 0.59 & 0.47 \\
Z-score, mean & -1.76 & 0.59 & & 91.00 \\
BPVS & & & 76.92 & $71-106$ \\
Raw, mean & 77.23 & 68.80 & $63-97$ & 0.49 \\
Raw, range & $47-107$ & $60-81$ & 0.35 & \\
Z-score, mean & -1.80 & 0.55 & & \\
\hline
\end{tabular}

Children were allocated to the control groups on the basis of their age. In order to determine how the G-SLI group compares to the control groups on the two language measures, a series of independent samples $t$-tests was performed. For the TROG, the SLI group did not perform significantly worse than the LA1 controls, $t(23)=-1.876$, $p=0.073$, but were significantly worse than, the LA2 controls $t(23)=-3.335, p=$ 0.003 , and the LA 3 controls, $t(23)=-4.750, p<0.001$. Even though the G-SLI and LA1 groups are not well-matched on the TROG, the LA1 group provides the closest match to the G-SLI group in terms of grammar ability. For the BPVS, the G-SLI group did not score significantly differently to the LA1 group, $t(23)=1.722, p=$ 0.105 , or the LA2 group, $t(23)=0.057, p=0.995$, but scored significantly worse than the LA3 group, $t(23)=-2.769, p=0.033$. The LA2 group provides the best match in terms of vocabulary ability, and the LA3 group is included to show the developmental pattern amongst the typically developing children.

\subsection{Design}

In order to test the predictions of the Computational Grammatical Complexity model, three sets of irregular verbs that differed in their phonological characteristics, with eight verbs in each set, were selected. The stimuli included one set of verbs ending with a vowel and another set ending in a non-alveolar consonant. The third set, ending in an alveolar consonant, comprised only vowel change rather than non-change verbs (e.g. hit, cut), so that correct tense-marking could be distinguished 
from null-marking errors. These verbs and their phonological and frequency characteristics are presented in Table 2.

Table 2 Phonological and frequency characteristics of irregular verbs

\begin{tabular}{|c|c|c|c|c|}
\hline Verb type & Phonological characteristics & Stimuli & Frequency $^{\mathrm{a}}$ & $\begin{array}{l}\text { Frequency } \\
\text { mean }(\mathrm{SD})\end{array}$ \\
\hline V & Ends in a long vowel/diphthong & $\begin{array}{l}\text { blow } \\
\text { grow } \\
\text { wear } \\
\text { tear } \\
\text { draw } \\
\text { fy } \\
\text { throw } \\
\text { see }\end{array}$ & $\begin{array}{l}2.585 \\
4.190 \\
4.190 \\
2.773 \\
4.195 \\
3.332 \\
3.850 \\
5.823\end{array}$ & $3.860(1.02)$ \\
\hline $\mathrm{t} / \mathrm{d}$ & Ends in an alveolar stop & $\begin{array}{l}\text { lead } \\
\text { bite } \\
\text { shoot } \\
\text { fight } \\
\text { get } \\
\text { read } \\
\text { ride } \\
\text { meet }\end{array}$ & $\begin{array}{l}4.419 \\
2.079 \\
2.944 \\
3.178 \\
5.823 \\
3.611 \\
3.714 \\
4.382\end{array}$ & 更 \\
\hline $\mathrm{C}$ & Ends in a non-alveolar consonant & $\begin{array}{l}\text { break } \\
\text { shake } \\
\text { steal } \\
\text { win } \\
\text { run } \\
\text { give } \\
\text { dig } \\
\text { choose }\end{array}$ & $\begin{array}{l}4.205 \\
4.060 \\
2.398 \\
3.829 \\
4.905 \\
5.656 \\
2.079 \\
3.638\end{array}$ & $3.846(1.19)$ \\
\hline
\end{tabular}

$\overline{{ }^{a} \text { Frequencies from Francis and Kucera (1982), calculated as } \ln (\text { raw frequency }+1) \text { for the past tense }}$ form of the verb

Verbs were chosen so that both their null-marked and correct past tense forms have the same phonological characteristics, as this makes assessing the impact of phonology on over-regularisation rates more straightforward. All conditions were well matched for the frequency of past tense forms, as past tense frequency impacts on both typically developing children and children with G-SLI (van der Lely and Ullman 2001). A one-way ANOVA revealed no frequency differences between conditions, $F(23)=0.017, p=0.983$.

In addition, there were 24 filler items, which were regular verbs with a variety of phonological forms. The rationale for introducing regular verbs was to provide variety, making it less likely that the child would fix on just one particular strategy for past tense formation, and to encourage over-regularisation errors, which were the particular focus of this experiment. 


\subsection{Procedure}

Stimuli were incorporated into an elicitation task of the sort widely used in tests of inflectional morphology (e.g. Marchman 1997; Oetting and Horohov 1997; van der Lely and Ullman 2001). The lead in was of the form "Everyday I get a present. Yesterday I (got a present)." In each sentence, the verb was followed by the indefinite article $a$ to ensure that if the -ed suffix was used, it could be heard more clearly. One randomised, set order was created for all participants. There were two practice sentences, using the high frequency irregulars go and have. The stimuli were presented live by the experimenter (first author), and responses were recorded onto a Sony DAT recorder.

\section{Results}

Responses were transcribed online during the testing session, and then subsequently checked against the recordings.

Responses were coded as follows:

- Correct, e.g. steal-stole

- Over-regularisation, e.g. throw-throwed; win-wonned; win-winneded (Note that three types of over-regularisations are possible here-suffixation of the base form (e.g. throwed), which is a simple over-regularisation, suffixation of the correct past tense form (e.g. wonnned) and suffixation of an already over-regularised form (e.g. winneded). Due to low numbers of the latter two types, all three are counted together in this analysis.)

- Null-marking, e.g. meet-meet

- Other, e.g. get-had; tear-did tear; steal-stolen, blow-blows, no response

The results are displayed in Table 3.

Table 3 Results

\begin{tabular}{llcccc}
\hline Verb type & Response type & G-SLI & LA1 controls & LA2 controls & LA3 controls \\
& & Mean \% (SD) & Mean \% (SD) & Mean \% (SD) & Mean \% (SD) \\
\hline V & Correct & $46.15(43.75)$ & $38.54(17.24)$ & $39.58(24.91)$ & $64.58(26.02)$ \\
& Over-regularisation & $21.15(26.21)$ & $52.08(14.92)$ & $48.96(26.36)$ & $33.33(26.83)$ \\
& Null-marking & $24.04(33.25)$ & $8.33(18.72)$ & $11.46(22.27)$ & $2.08(4.87)$ \\
Other & $8.65(16.36)$ & $1.04(3.61)$ & $0(0)$ & $0(0)$ \\
& Correct & $41.35(40.23)$ & $40.63(27.76)$ & $50.00(26.11)$ & $80.21(18.81)$ \\
& Over-regularisation & $15.39(24.56)$ & $32.29(27.42)$ & $31.25(27.95)$ & $14.58(15.84)$ \\
& Null-marking & $34.62(39.91)$ & $22.92(34.47)$ & $16.62(28.37)$ & $2.08(7.22)$ \\
Other & $9.62(17.04)$ & $4.17(8.14)$ & $2.08(4.84)$ & $3.13(5.65)$ \\
Correct & $49.04(42.89)$ & $56.35(27.95)$ & $57.29(26.36)$ & $87.50(15.99)$ \\
& Over-regularisation & $17.33(28.63)$ & $30.21(18.04)$ & $28.13(25.63)$ & $11.46(14.56)$ \\
& Null-marking & $25.96(31.23)$ & $11.46(26.36)$ & $9.38(17.78)$ & $1.04(3.61)$ \\
& Other & $7.69(10.87)$ & $2.08(4.86)$ & $3.13(5.65)$ & $0(0)$ \\
\hline
\end{tabular}


We analyse the results according to each of the predictions made by the Computational Grammatical Complexity model, which were set out in Sect. 1.3.

\subsection{Syntax}

The syntactic prediction was that children with G-SLI mark tense less frequently than typically developing children. The G-SLI group was therefore predicted to produce fewer correct forms+over-regularisations. We calculated this variable, named "tensemarking", for the four groups, and the data are presented in Fig. 1. We investigated the effect of group on tense-marking using a one-way ANOVA, and this effect was indeed significant, $F(3,48)=4.56, p=0.007$. The significant effect of group was followed up with post hoc tests using the Games-Howell correction due to unequal variances. The G-SLI group marked tense significantly less often the LA3 group, $p=0.004$, but not significantly less than the LA $1, p=0.201$, or LA2, $p=0.238$, groups. None of the control groups differed significantly from one another: for the comparison between LA1 and LA2, $p=1.000$, for LA1 and LA3, $p=0.296$, and for LA2 and LA3, $p=0.128$.

A second prediction, related to the first, was that the G-SLI group would produce more null-marking errors. These data are shown in Fig. 2. A one-way ANOVA shows that group differences just fail to reach significance, $F(3,48)=2.63, p=0.061$.

\subsection{Morphology}

The morphological prediction was that the G-SLI group will produce fewer overgeneralisation errors. The relevant data are presented in Fig. 3. We tested this prediction using a one-way ANOVA, and this yielded a significant effect of group, $F(3,48)=4.29, p=0.010$. Post-hoc Games-Howell tests revealed that children with G-SLI produced fewer over-regularisations than the LA1 group, $p=0.037$, and fewer than the LA2 group, although this difference did not reach significance, $p=0.109$. There was no significant difference between the G-SLI and the LA3 groups, $p=0.992$. Nor was there a significant difference in the number of over-regularisations produced by the LA1 and LA2 groups, $p=1.00$, or the LA2 and LA3 groups, $p=0.155$, but the

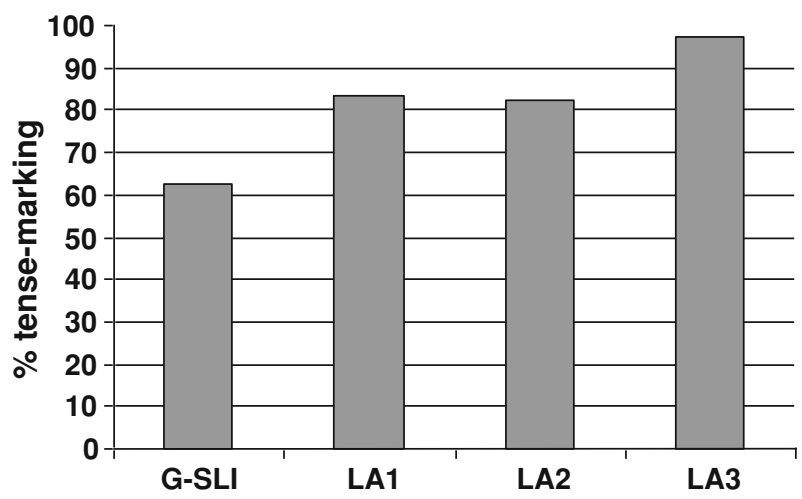

Fig. 1 Testing the syntactic prediction: \% tense-marking (i.e. correct + over-regularised forms) 


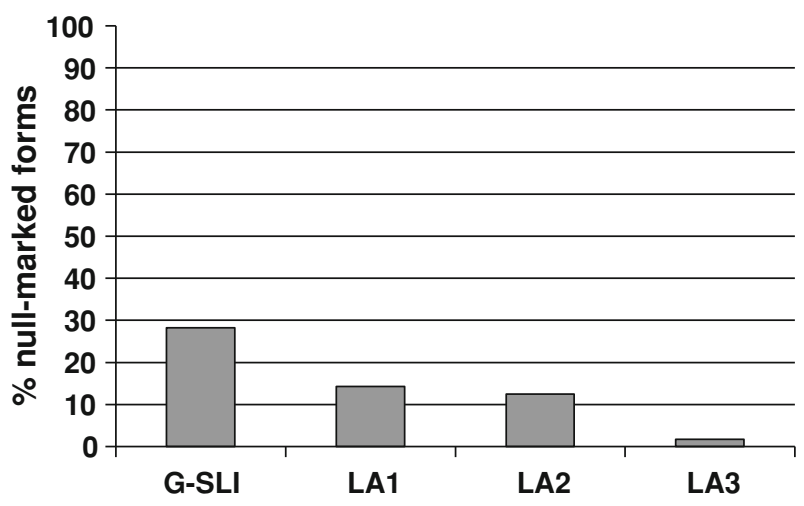

Fig. 2 Testing the syntactic prediction: \% null-marked forms

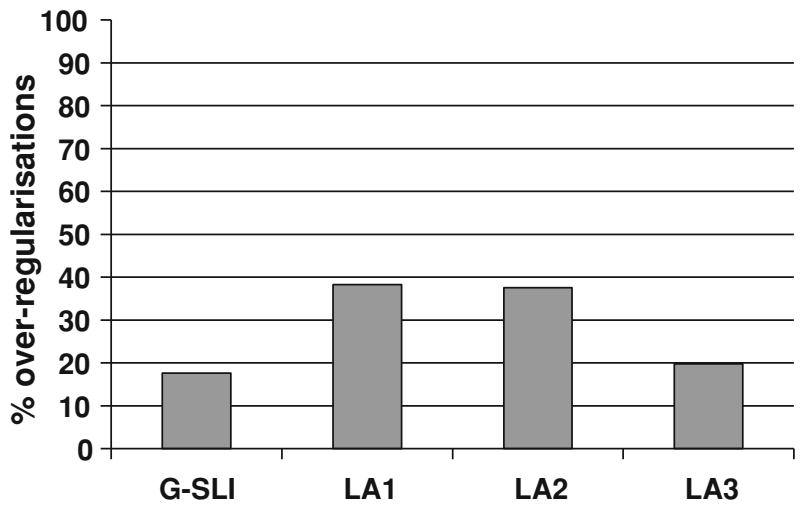

Fig. 3 Testing the morphological prediction: \% over-regularisation errors

LA1 group produced marginally more over-regularisation errors than the LA3 group, $p=0.055$. That the LA3 group produce few over-regularisations is not surprising given their high level of accuracy in the task - they had fewer opportunities for making an over-regularisation error compared to the G-SLI, LA1 and LA2 groups.

One further way of analysing over-regularisation errors, which takes into account these fewer opportunities with increasingly correct responses, is to investigate whether all groups show the same relative behaviour with respect to the proportion of over-regularisation and null-marking errors, or whether the G-SLI group show a different pattern relative to the controls. A 2(error: over-regularisation, null-marking) $\times 4$ (group) ANOVA revealed a significant interaction, $F(3,45)=2.99$, $p=0.041$, and a significant main effect of error, $F(1,45)=8.17, p=0.006$. Following up the interaction with a series of paired samples $t$-tests revealed that the G-SLI group showed no significant difference in the number of over-regularisation and null-marking errors they produce, $t(12)=-0.885, p=0.394$. In contrast all three control groups were significantly more likely to over-regularise than to not mark tense, $t(11)=2.293, p=0.043, t(11)=2.348, p=0.039$, and $t(11)=3.532$, 
$p=0.005$, for LA1, LA2 and LA3 respectively, although with an alpha level set at 0.013 to correct for multiple comparisons this difference remains significant only for the LA3 group.

\subsection{Phonology}

The phonological prediction was that both the number of over-regularisations and the number of bare stem errors would be affected by phonology, and that this would be the case for all the groups, G-SLI and control. Specifically, there would be fewer over-regularisations and more null-marking on verbs that end in either an alveolar consonant, where the syllabic allomorph is required, or a non-alveolar consonant, where a cluster would result.

The effect of phonology on over-regularisations is shown in Fig. 4 and was explored in a 3(verb type: $\mathrm{V}, \mathrm{t} / \mathrm{d}, \mathrm{C}$ ) by 4(group) repeated measures ANOVA. Due to a violation of assumptions of sphericity, we used the Greenhouse-Geisser correction. There was a significant effect of verb type, $F(1.77,79.62)=13.58$, $p<0.001$, but this did not interact with group, $F(1.53,79.62)=0.84, p=0.533$. There was a significant effect of group, in line with what we reported earlier for over-regularisations in Sect. 3.2, $F(3,45)=3.97, p=0.014$.

The significant effect of verb type was followed up by series of paired samples $t$-tests with data pooled from all groups (as there was no interaction), with the alpha level set at 0.017 to compensate for multiple comparisons. Over-regularisation was significantly more likely for $\mathrm{V}$ than $\mathrm{C}$ verbs, $t(48)=4.701, p<0.001$, and significantly more likely for $\mathrm{V}$ than $\mathrm{t} / \mathrm{d}$ verbs, $t(48)=3.693, p=0.001$. No significant difference was found between $\mathrm{C}$ and $\mathrm{t} / \mathrm{d}$ verbs, $t(48)=-0.511, p=0.612$.

The effect of verb type on null-marking errors is shown in Fig. 5 and explored in a 3(verb type: V, t/d, C) by 4(group) repeated measures ANOVA with GreenhouseGeisser correction. The effect of verb end was significant, $F(1.55,69.60)=7.00$, $p=0.004$, but the interaction was not, $F(4.64,69.60)=1.05, p=0.395$. The effect of group was only marginally significant, $F(3,45)=2.63, p=0.062$, again in line with what we report above, in Sect. 3.1. The significant effect of verb type was

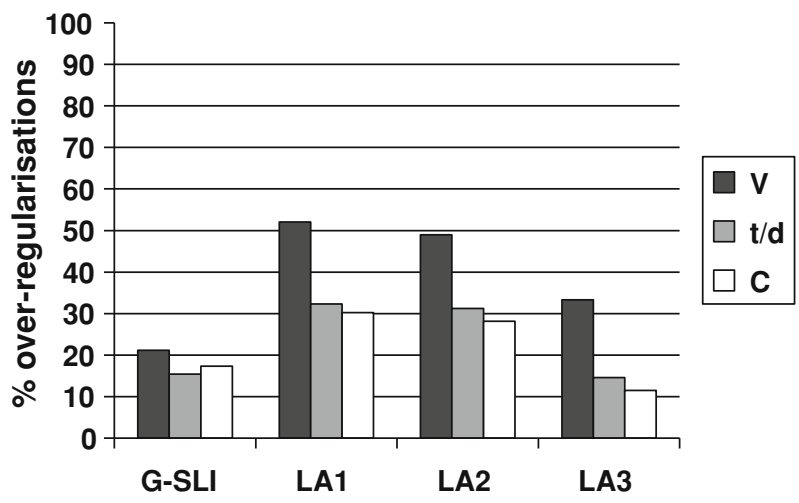

Fig. 4 Testing the phonological prediction: effect of phonology on over-regularisations 


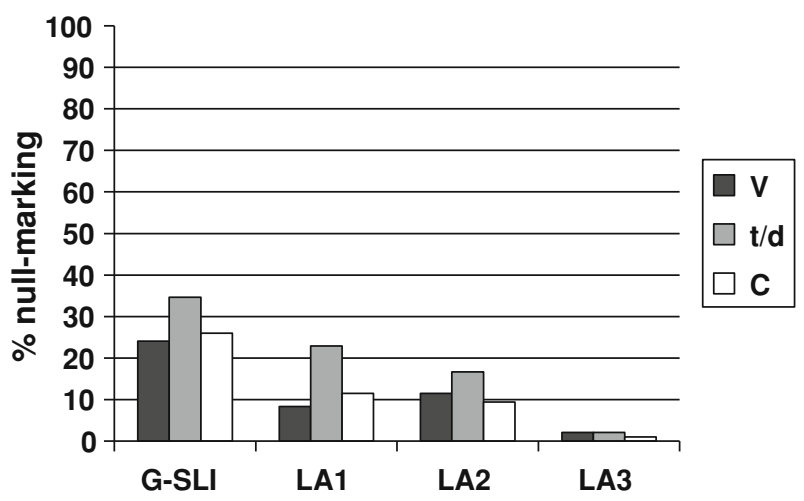

Fig. 5 Testing the phonological prediction: effect of phonology on null-marking

followed up by series of paired samples $t$-tests with data pooled from all groups, with the alpha level again set at 0.017 . Null-marking was significantly more likely for $\mathrm{t} / \mathrm{d}$ than $\mathrm{V}$ verbs, $t(48)=-2.785, p=0.008$, and significantly more likely for $\mathrm{t} / \mathrm{d}$ than $\mathrm{C}$ verbs, $t(48)=-3.060, p=0.004$, but null-marking on $\mathrm{C}$ and $\mathrm{V}$ verbs did not differ significantly, $t(48)=-0.321, p=0.749$.

\section{4 "Other" errors}

The final analysis is on the proportion of "other" errors in each group, i.e. errors that are not over-regularised or null-marked forms. As can be seen from Table 3, the G-SLI group produce more "other" errors than the control groups, and a one-way ANOVA confirms that the proportion of "other" errors is significantly affected by group, $F(3,48)=3.86, p=0.015$. However, under post hoc Games-Howell testing, all pairwise group comparisons are non-significant $(p>0.150)$

Of note is that some of the "other" errors produced by the children with G-SLI were not produced by the typically developing children. Examples include "will get", "am lead", "speeching" (target: "gave a speech") and "steal a watched" (target: "stole a watch"). Identical errors occurred with the regular fillers, e.g. "am whistle" and "am marrying a dancered" (target: "married a dancer").

\subsection{Summary}

The impact of a syntactic deficit on irregular past tense formation in children with G-SLI (aged 9;8-17;8) is shown by that group using tense-marking less frequently than children who are chronologically younger. Large standard deviations prevented the comparison with the LA1 $(5 ; 4-6 ; 6)$ and LA2 $(6 ; 7-7 ; 6)$ groups reaching significance, but the G-SLI group did use tense-marking significantly less frequently than the LA3 controls, children who were 7;9-8;5. This is despite the G-SLI group being considerably older.

With respect to the morphological deficit, the G-SLI group produced significantly fewer over-regularisations than the LA1 group, and fewer over-regularisations than the LA2 group, although this difference did not reach significance. They did not 
differ in the number of over-regularisation errors relative to the LA3 controls, but the LA3 group were more accurate in supplying the correct form of the irregular past tense and so have fewer opportunities for over-regularisation. Furthermore, the LA3 group were significantly more likely to produce an over-regularisation error than to not mark tense, whereas for the G-SLI group there was no significant difference in the number of over-regularisation and null-marking errors.

In addition, the impact of a phonological deficit is clearly seen in children with G-SLI. The G-SLI group remain affected by the phonological factors that affect over-regularisation and null-marking in much younger typically developing children, namely complexity at the syllabic and metrical levels. They are more likely to add a suffix to the verb, i.e. to over-regularise, when the verb ends in a vowel. In contrast they are more likely to null-mark verbs that end in an alveolar consonant.

\section{Discussion}

Irregular past tense forms are unlike regulars in that they can be marked for tense in one of two ways - by using the correct form, which is idiosyncratic to each verb and needs to be retrieved from the lexicon, or, if lexical retrieval fails, by the addition of the suffix -ed to the verb stem, i.e. over-regularisation. This study tests the prediction of the Computational Grammatical Complexity model that for children with Grammatical-Specific Language Impairment (G-SLI), syntactic, morphological and phonological deficits all impact on the form of the irregular verb that is produced in past tense contexts. Should this be the case, this evidence would in turn offer support for a model of morphology whereby a distinction needs to be made between "words" and "rules", but which in addition recognizes the contribution of phonology to the construction of morphologically complex forms.

With respect to syntax, children and young adults with G-SLI, who in our study were aged 9;8-17;8, tense-marked irregular forms less frequently than typically developing children who, at an age of 7;9-8;5, are considerably younger. With respect to morphology, the G-SLI group produces significantly fewer over-regularisations compared to even younger typically developing children (aged 5;4-6;6). With respect to phonology, children with G-SLI were still affected by syllabic and metrical complexity, factors that affect over-regularisation and null-marking in typically developing children aged 5;4-8;5. Children were more likely to add a suffix to the verb, i.e. to over-regularise, when the verb ends in a vowel. In contrast they were more likely to null-mark verbs that end in an alveolar consonant, a finding that is in line with previous results from typically developing children (Bybee and Slobin 1982; Marchman 1997; Matthews and Theakston 2006). As well as revealing the effect of complexity in different components of the grammar on past tense inflection in children with G-SLI, our data also confirm the persistence of the impairment into even the teenage years. Presumably it is the cumulative impact of impairments in three components of grammar that makes past tense such a reliable clinical marker for SLI.

When coding over-regularisations, we came across many examples of suffixation to the base form, e.g. throw-throwed: for all groups these were the most common type of over-regularisation. In addition however, all groups produced at least one 
example of adding the suffix to a correct irregular past tense form: flewed, wored and gaved (G-SLI group); wonned and stoled (LA1), ranned, chosed and broked (LA2), and tored (LA3). A third type of over-regularisation, a double suffixation, occurred only in the G-SLI group, and there was only one example of it: winneded. However, there were more examples of double suffixation for the regular fillers from three different G-SLI children, including paided, tieded, cheweded and roweded. In contrast, there were no double-suffixed forms in the regular data from the typically developing children.

Our data contained examples of children using a syllabic suffix instead of the expected consonantal suffix. ${ }^{2}$ There were four examples for the G-SLI group, on gave, shake, break, and dig. There was only one example each for the LA1 and LA2 groups, both on choose. There are two possible reasons for this error-either it is to the result of cluster avoidance, or it indicates selection of the wrong allomorph. It is difficult to draw conclusions from so few examples, but the fact that each of these errors occurs with consonant-final stems, and not with vowel-final stems, indicates cluster avoidance. This then would be further evidence that phonological complexity affects the production of morphologically complex forms.

It is also worth noting that despite the lack of significant pairwise group comparisons for "other" errors, the G-SLI children produced more of these errors than the typically developing controls. This is not due to the G-SLI group producing more errors overall: the G-SLI and LA1 groups showed almost identical errors rates-54.49 and 54.83\% respectively, and yet "other" errors constituted $15.88 \%$ of errors in the G-SLI group and only $4.43 \%$ of errors in the LA1 group. Some of the "other" errors produced by children with G-SLI were not produced by any of the control children (e.g. "will get", "steal a watched"; see Sect. 3.4). We are not claiming that the G-SLI children produce responses that would never be found in typical development, just that some of these responses did not occur in our control groups. Such errors can, however, be found in the speech of younger children. For example, the Manchester Corpus of 2-year-old children's conversational language (available on the CHILDES database, Theakston et al. 2001) reveals that children this young occasionally mark other parts of speech (e.g. it come outed, it fall down-ed, just get all catched Thomas-ed).

Meanwhile, our findings are consistent with a study of plural inflection in 5-yearold Dutch children with SLI by de Bree and Kerkhoff (2010), which found that children with SLI produce a significant proportion of "other" responses, at an age where they are much rarer in typical development. Overall, "other" responses have previously received little attention in the morphological literature. However, a relevant comparison can be made with non-word repetition, a phonological task where children are asked to repeat a set of nonsense words that vary in their phonological characteristics, for example their number of syllables, word-likeness or syllabic structure. Like inflectional morphology, non-word repetition has been suggested as a clinical marker for SLI in English (Bishop et al. 1996), as children with SLI have severe difficulties in repeating non-words accurately. Of relevance to the present study is that whereas the majority of typically developing children's

\footnotetext{
${ }^{2}$ These were counted as being over-regularised, rather than as "other" errors, given that a suffix had been provided.
} 
non-word repetition errors are easy to classify and they tend to make just one error (e.g. one consonant cluster simplification) per non-word, children with SLI make more multiple errors within a non-word, and, unlike for typically developing children, the proportion of multiple errors increases with increasing syllable length (Marton 2006). We suggest that across these two components of language-morphology and phonology - the performance of children with SLI can be characterised by more varied and more complex error patterns than those seen in typically developing children, and that this warrants further exploration.

The effects of a phonological deficit on inflectional morphology are becoming increasingly recognised by researchers of SLI. For example, Haskill and Tyler (2007) found that 4-year-old children with syntactic plus phonological impairments were significantly less accurate at producing noun plural $-s$ and third person singular $-s$ in semi-structured conversational contexts than 4 year-olds with just a syntactic impairment. Certain final clusters were particularly difficult for children who had a phonological impairment in addition to their syntactic impairment, namely -/ts/, -/mz/, -/nts/, -/ks/ and -/gz/. For Dutch, Rispens and Been (2007) showed that 8year-old children with SLI have difficulties in detecting subject-verb agreement violations, and they suggested that this might be linked with poor phonology. Relevant to this proposal was the finding that children with SLI had particular difficulties with a phoneme-deletion task, whereby they were asked to delete the word-final consonant from a set of real words (Rispens and Been 2007).

Our findings and interpretation are also in line with recent research studies of typically developing children that highlight the importance of phonology in the early acquisition of morphology, alongside factors such as syntax and lexical frequency. For example, Kerkhoff (2007) has stressed the interplay between lexical frequency, morphology and phonology (specifically, the ability to distinguish between voiced and unvoiced consonants in perception and production) in Dutch children's acquisition of the alternating plural, e.g. [bet] $\sim$ [bedən]. Demuth and her colleagues have carried out a series of studies, in languages as diverse as English, French and Sesotho, investigating how children can produce grammatical morphemes, be they prefixes, suffixes or function words, only when they are prosodically licensed (Demuth et al. 2009; Demuth and McCullough 2009; Demuth and Tremblay 2008; Song et al. 2009).

\section{Conclusion}

The study of irregular past tense morphology reported in this paper complements studies of regular past tense inflection in revealing the cumulative effects of deficits in syntax, morphology and phonology on the construction of morphologically complex forms (van der Lely 2005; Marshall and van der Lely 2006, 2007a). Together these findings provide support for a model of morphology where regular forms are created by a rule whereas irregular forms are stored in the lexicon, and where phonology has a significant impact on the actual form of the verb that is produced.

Acknowledgments We would like to thank the children who took part in the study, their parents, and the staff from the following schools: Dawn House School (Nottinghamshire), Moor House School 
(Surrey), Whitefield School (Walthamstow), Ifield Infant and Middle Schools (West Sussex), Brockham Primary School (Surrey) and Southgate Infant School (West Sussex). This work was funded by an Economic and Social Research Council postgraduate studentship to Chloë Marshall, and a Wellcome Trust University Award GR063713 to Heather van der Lely. The writing of this manuscript was supported by an Early Career Fellowship from the Leverhulme Trust to Chloë Marshall, and an EU Lifelong Learning Programme grant no: 2007-1992 001/001 TRA STUCOR awarded to HvdL.

Open Access This article is distributed under the terms of the Creative Commons Attribution Noncommercial License which permits any noncommercial use, distribution, and reproduction in any medium, provided the original author(s) and source are credited.

\section{References}

Berko, J. (1958). The child's learning of English morphology. Word, 14, 150-177.

Bishop, D. V. M. (1983). Test for reception of grammar. Published by the author and available from the Age and Cognitive Performance Research Centre, University of Manchester, M13 9PL.

Bishop, D. V. M., North, T., \& Donlan, C. (1996). Non-word repetition as a behavioural marker for inherited language impairment: Evidence from a twin study. Journal of Child Psychology and Psychiatry, 37, 391-403.

Braber, N., Patterson, K., Ellis, K., \& Lambon Ralph, M. (2005). The relationship between phonological and morphological deficits in Broca's aphasia: Further evidence from errors in verb inflection. Brain and Language, 92, 278-287.

Brown, R. (1973). A first language: The early stages. Cambridge, MA: Harvard University Press.

Bybee, J., \& Slobin, D. (1982). Rules and schema in the development and use of the English past tense. Language, 58, 265-289.

de Bree, E., \& Kerkhoff, A. (2010). Bempen or bemben: Differences between children at-risk of dyslexia and children with SLI on a morpho-phonological task. Scientific Studies of Reading, 14, 85-109.

de Villiers, J., \& de Villiers, P. (1973). A cross-sectional study of the acquisition of grammatical morphemes in child speech. Journal of Psycholinguistic Research, 2, 267-278.

Demuth, K., Machobane, M., \& Moloi, F. (2009). Learning to license null noun class prefixes in Sesotho. Language, 85, 864-883.

Demuth, K., \& McCullough, E. (2009). The prosodic (re)organization of children's early English articles. Journal of Child Language, 36, 173-200.

Demuth, K., \& Tremblay, A. (2008). Prosodically-conditioned variability in children's production of French determiners. Journal of Child Language, 35, 99-127.

Dunn, L. M., Dunn, L. M., Whetton, C., \& Burley, J. (1997). British picture vocabulary scales (2nd Ed.). Windsor: NFER Nelson.

Francis, W. N., \& Kucera, H. (1982). Frequency analysis of English usage: Lexicon and grammar. Boston, MA: Houghton Mifflin.

Gallon, N., Harris, J., \& van der Lely, H. K. J. (2007). Nonword repetition: An investigation of phonological complexity in children with Grammatical-SLI. Clinical Linguistics and Phonetics, 21, 435-455.

Haskill, A. M., \& Tyler, A. A. (2007). A comparison of linguistic profiles in subgroups of children with Specific Language Impairment. American Journal of Speech-Language Pathology, 16, 209-221.

Joanisse, M. (2004). Specific Language Impairments in children: Phonology, semantics and the English past tense. Current Directions in Psychological Science, 13, 156-160.

Joanisse, M., \& Seidenberg, M. (1998). Specific language Impairment: A deficit in grammar or processing? Trends in Cognitive Science, 2, 240-247.

Joanisse, M., \& Seidenberg, M. (1999). Impairments in verb morphology following brain injury: A connectionist model. Proceedings of the National Academy of Sciences, USA, 96, 7592-7597.

Kerkhoff, A. (2007). Acquisition of morpho-phonology: The Dutch voicing alternation. LOT, Dissertation University of Utrecht, Utrecht.

Kielar, A., Joanisse, M., \& Hare, M. (2008). Priming English past tense verbs: Rules or statistics? Journal of Memory and Language, 58, 327-346.

Leonard, L. (1998). Children with specific language impairment. Cambridge, MA: MIT Press.

Leonard, L., McGregor, K., \& Allen, G. (1992). Grammatical morphology and speech perception in children with specific language impairment. Journal of Speech and Hearing Research, 35, 1076-1085. 
Marchman, V. (1997). Children's productivity in the English past tense: The role of frequency, phonology and neighbourhood structure. Cognitive Science, 21, 283-304.

Marchman, V., Wulfeck, B. \& Weismer, S. (1999). Morphological productivity in children with normal language and SLI: A study of the English past tense. Journal of Speech, Language and Hearing Research, 42, 206-219.

Marcus, G. F., Pinker, S., Ullman, M., Hollander, M., Rosen, T. J., \& Xu, F. (1992). Overregularisation in language acquisition. Monographs of the Society for Research in Child Development, 57, 4, Serial No. 228.

Marshall, C. R., Marinis, T., \& van der Lely, H. K. J. (2007). Passive verb morphology: The effect of phonotactics on passive comprehension in typically developing and Grammatical-SLI children. Lingua, 117, 1434-1447.

Marshall, C. R., \& van der Lely, H. K. J. (2006). A challenge to current models of past tense inflection: The impact of phonotactics. Cognition, 100, 302-320.

Marshall, C. R., \& van der Lely, H. K. J. (2007a). The impact of phonological complexity on past tense inflection in children with Grammatical-SLI. Advances in Speech-Language Pathology, 9, 191-203.

Marshall, C. R., \& van der Lely, H. K. J. (2007b). Derivational morphology in children with Grammatical-Specific Language Impairment. Clinical Linguistics and Phonetics, 42, 71-91.

Marslen-Wilson, W. D., \& Tyler, L. K. (1997). Dissociating types of mental computation. Nature, 387, 592-594.

Marton, K. (2006). Do nonword repetition errors in children with specific language impairment reflect a weakness in an unidentified skill specific to nonword repetition or a deficit in simultaneous processing? Applied Psycholinguistics, 27, 569-573.

Matthews, D. E., \& Theakston, A. L. (2006). Errors of omission in English-speaking children's production of plural and past tense: The effects of frequency, phonology and competition. Cognitive Science, 30, 1027-1052.

McClelland, J. L., \& Patterson, K. (2002). Rules or connections in past-tense inflections: What does the evidence rule out? Trends in Cognitive Sciences, 61, 465-472.

Oetting, J., \& Horohov, J. (1997). Past-tense marking by children with and without specific language impairment. Journal of Speech, Language, and Hearing Research, 40, 62-74.

Pinker, S. (1999). Words and rules: The ingredients of language. London: Weidenfeld \& Nicolson.

Pinker, S., \& Ullman, M. (2002). The past and future of the past tense. Trends in Cognitive Sciences, 6, 456-463.

Polite, E. (2011). The contribution of part-word phonological factors to the production of regular noun plural $-s$ by children with and without specific language impairment. First Language, 31, 425-441.

Rice, M. (2003). A unified model of specific and general language delay: Grammatical tense as a clinical marker of unexpected variation. In Y. Levy \& J. Schaeffer (Eds.), Language competence across populations: Toward a definition of specific language impairment. (pp. 63-94). Mahwah, NJ: Lawrence Erlbaum Associates

Rice, M., \& Wexler, K. (1996). Towards tense as a clinical marker of specific language impairment in English-speaking children. Journal of Speech and Hearing Research, 39, 1239-1257.

Rispens, J. E., \& Been, P. H. (2007). Subject-verb agreement and phonological processing in developmental dyslexia and SLI: A closer look. International Journal of Language and Communication Disorders, 42, 293-305.

Rumlehart, D. E., \& McClelland, J. L. (1986). On learning the past tenses of English verbs. In J. L. McClelland, D. E. Rumelhart, \& PDP Research Group. (Eds.), Parallel distributed processing: Explorations in the microstructure of cognition (Vol. 2, pp. 216-271). Cambridge, MA: Bradford/ MIT Press

Shipley, K. G., Maddox, M. A., \& Driver, J. E. (1991). Children's development of irregular past tense forms. Language, Speech and Hearing Services in Schools, 22, 115-122.

Song, J. Y., Sundara, M., \& Demuth, K. (2009). Phonological constraints on children's production of English third person singular -s. Journal of Speech, Language and Hearing Research, 52, 623-642.

Theakston, A. L., Lieven, E. V. M., Pine, J. M., \& Rowland, C. F. (2001). The role of performance limitations in the acquisition of verb-argument structure: An alternative account. Journal of Child Language, 28, 127-152.

Ullman, M. (1999). Acceptability ratings for regular and irregular past tense forms. Evidence for a dualsystem model of language from word frequency and phonological neighbourhood effects. Language and Cognitive Processes, 14, 46-67.

Ullman, M., Corkin, S. Coppola, M., Hickok, G., Growdon, J. H., Koroshetz, W. J., \& Pinker, S. (1997). A neural dissociation within language: Evidence that the mental dictionary is part of declarative 
memory and that grammatical rules are processed by the procedural system. Journal of Cognitive Neuroscience, 9, 266-276.

Ullman, M. T., Pancheva, R., Love, T., Yee, E., Swinney, D., \& Hickok, G. (2005). Neural correlates of lexicon and grammar: Evidence from the production, reading, and judgment of inflection in aphasia. Brain and Language, 93, 185-238.

van der Lely, H. K. J. (2005). Domain-specific cognitive systems: Insight from Grammatical specific language impairment. Trends in Cognitive Sciences, 9, 53-59.

van der Lely, H. K. J., \& Marshall, C. R. (2011). Grammatical-Specific Language Impairment: A window onto domain-specificity. In J. Guendouzi, F. Loncke, \& M. Williams (Eds.), The handbook of psycholinguistic and cognitive processes: Perspectives in communication disorders. (pp. 401-418). New York: LEA, Taylor \& Francis.

van der Lely, H. K. J., Rosen, S., \& McClelland, A. (1998). Evidence for a grammar-specific deficit in children. Current Biology, 8, 1253-1258.

van der Lely, H. K. J., \& Stollwerck, L. (1997). Binding theory and grammatical specific language impairment in children. Cognition, 62, 245-290.

van der Lely, H. K. J., \& Ullman, M. (1996). The computation and representation of past-tense morphology in normally developing and specifically language impaired children. In A. Stringfellow, D. Cahana-Amitay, E. Hughes, \& A. Zukowski (Eds.), Proceedings of the 20th annual Boston University conference on language development (Vol. 2, pp. 792-803). Somerville, MA: Cascadilla Press.

van der Lely, H. K. J., \& Ullman, M. (2001). Past tense morphology in specifically language impaired children and normally developing children. Language and Cognitive Processes, 16, 177-217. 